known, and this is obviausly an extensive field for research. Larval Thalassinids form a large part of the plankton, especially inshore. "In one quarterhour haul at Broken Bay in April 1935, there were hundreds of thousands of larvæ in different stages." Gurney, in the "Discovery" Reports (1938), has shown that there are many more Thalassinid larvæ than known adults (especially belonging to the Axiid-Callianassid group). Here again in Sydney Harbour the adults are not known, except in a very few instances. The larvæ occur at certain stated times. It will be interesting to hear of more researches on these forms-a difficult subject, as these Tha. lassinids live in very inaccessible places, and there must be an enormous number of undescribed species. The present work deals mainly with invertebrates, but there is a small section on fish eggs. Further work on these and on other groups here not fully dealt with are subjects for the future.

\section{War-Time Medicinal Formulæ}

THE direction of the policy which is being adopted in the compilation of war-time formulæ for medicinal preparations is indicated by the nature of the recommendations recently made by the British Pharmaceutical Codex Revision Committee. It may well be that there is little need to replace all those drugs now unobtainable by alternative substances. On the other hand, it is very desirable that authoritative guidance should be given to prescribers as to substitutes for at least some of the scarce or unobtainable drugs, and also as to the best combinations in which to present them. This duty falls upon several bodies recognized as being properly constituted for the purpose, and one such is the Codex Revision Committee.

The recommendations made by this body are not restricted to the replacement of scarce substances by those which are more freely available. They cover a wider field. Thus it is proposed to authorize the use of tap water in place of distilled water except in injections and in preparations for which the pharmacist may consider distilled water more suitable. To the patient who invariably uses tap water to dilute his medicines, where dilution is directed, there appears to be nothing remarkable in this recommendation and there would seem to be little reason why it should not continue to be applied in peacetime. With regard to alcohol the Committee, following the advice of the Medical Research Council, that, in order to observe economy in the use of alcohol, many tinctures should be replaced by concentrated preparations, agrees that concentrated liquid extracts should be employed instead of tinctures and has decided to draw up a list of liquid extracts which might be used for this purpose. Other recommenda. tions have their origin in the scarcity of tragacanth, squill, liquid paraffin, olive oil and almond oil.

\section{Food Growing and Utilization}

IT is fully recognized that the amateur gardeners and allotment holders of Great Britain are making a vital contribution to the war effort. Maximum erops need to be raised and any wastage through faulty storage or cooking must be avoided. The "Penguin Book of Food Growing, Storing and Cooking", by Mr. F. W. P. Carter, provides much practical information in a simple manner on these subjects (Penguin Special, S.90. Harmondsworth : Penguin Books, Ltd. 6d.). Crops are dealt with alphabetically which makes reference simple. The method of cultivation, recommended varieties, quantity of seed required, likely pests and their control, storage and where possible also cooking methods are described for all the more commonly grown vegetables. Good general information is also given regarding the preparation of the soil. The booklet concludes with simple suggestions for garden work each month and a detailed cropping plan for a period of three years on a typical allotment.

The correct utilization of food is dealt with by Mr. Frank Wokes in another Penguin Special, "Food: the Deciding Factor" (S. 87. 6d. Much information on food values and diet is compressed into a small space. The energy and body-building values of different types of food are explained, and diets suggested which make for properly balanced meals, rationing being taken into account. A considerable part of the booklet is devoted to the question of vitamins, the quantities required and the foods which supply them. Interesting tables are given in the appendix showing the body-building and energy values, mineral and vitamin contents of a large number of generally consumed articles of food, including cereals, dairy produce, fish, fruit, meat and nuts.

\section{Institute of Physics : Industrial Radiology Group}

For some considerable time, physicists engaged in the various branches of industrial radiology have expressed a wish for some means whereby they could come together for the mutual discussion of their particular problems. Accordingly, the London and Home Counties' Branch of the Institute of Physics arranged a Conference on Industrial Radiography in January 1941 (see Naxure, February 8, p. 183). As a result of this Conference it was decided to ask the Board of the Institute of Physics to approve the formation of a Radiography Group. The Board's approval having been obtained, the inaugural meeting of the Group was held on May 20, at the Social Centre of Messrs. Kodak, Ltd., Harrow, about seventy people attending - some coming from as far afield as Leven, Motherwell, Sheffield and Derby. The title "Industrial Radiology Group" being approved by those present, Dr. L. Mullins, of the Research Laboratory of Messrs. Kodak, Ltd., was appointed honorary secretary, and the following committee was elected: Drs. W. Betteridge, D. W. Davison, and H. Lowery, Messrs. A. N. Gilehrist, W. L. Harper, H. P. Rooksby, H. S. Tasker, D. E. Thomas, and E. J. Tunnicliffe.

So constituted, the present committee is representative of those concerned with the industrial applications of radiography and X-ray crystallography and of those engaged in the manufacture of industrial X-ray apparatus and X-ray films. In addition, the British Institute of Radiology and the 
Society of Radiographers are to be asked to send one representative each to serve on the committee. This committee was given power to elect its own chairman and to formulate a constitution for the Group. In addition to providing a medium for the exchange of views and experiences on the practice of radiography and $\mathrm{X}$-ray crystallography in industry, it is to be hoped that the Group may ultimately issue a report summarizing many of the essential practical points of importance to users of X-ray plant, as one noticed at the above-mentioned Conference that many quite elementary matters of technique were not generally known in the various industries employing X-rays. Membership of the Industrial Radiology Group is open to all who are interested, whether or not they are at present members of the Institute of Physics.

\section{Association of Scientific Workers}

THE annual council meeting of the Association of Scientific Workers was held in Birmingham on May 24 and 25 ; eighty delegates were present representing scientific workers and engineers in industrial and Government posts as well as university staff and students. As this was the first council meeting to be held since the registration of the Association as a trade union, the reports presented, and the ensuing discussion, were chiefly concerned with the planning of an industrial policy for the Association. Discussion centred mainly around a report by the Industrial Sub-Committee which analysed the present conditions of scientific and engineering staff. This report showed that even under peace-time conditions, there is a considerable difference between salaries paid to people having the same qualifications but employed by different firms. In the engineering industry, for example, the general salary level is notably less than in certain chemical firms. Increments were often obtained by negotiation between the employer and the individual, but war-time restrictions on change of employment have removed the individual's chief bargaining instrument. A survey among members of the Association shows that there is a marked tendency in industry for no increments to be given, while in Government establishments war-time posts carry a fixed salary.

It was pointed out in the discussion that cancellation of increments is particularly unfair to the younger scientific workers whose salaries are frozen at the low starting figure. Attention was also directed to the injustices caused by failure to grant payment for overtime to many scientific workers and engineers. It was said to be a common experience, particularly in large firms, for hours of work and holidays to be altered suddenly without consultation with the unorganized sections of the staff. The conclusion drawn by the Industrial Sub-committee of the Association and endorsed by the council meeting is that collective action through the Association is the only effective method by which engineers and scientific workers can safeguard their conditions, and bring them into relationship with those of organized sections of industry: The council unanimously adopted a resolution in favour of close co-operation between the Association and other trade unions.

\section{Mummification in America}

Reference has already been made (NAture, April 5, p. 413) to the first part of a description by Dr. Aleš Hrdlička, curator of physical anthropology in the U.S. National Museum, of investigations undertaken in mummy caves and rock shelters in the Aleutian Islands off the coast of Alaska (Scientific Monthly, Jan.-Feb. 1941). It would appear that. the aboriginal inhabitants were at some unknown period replaced by the Aleuts, among whom, comparatively lately, Russian penetration took place. The Aleuts practised mummifying, though whether they began to do so after their arrival in the islands. or whether they brought the custom with them from their unknown place of origin remains a mystery. The mummies of both sexes were stored in the caves lying upon driftwood, and differences of physical anthropology among them suggest that a few members of the pre-Aleut people had been allowed to survive, perhaps in a condition of slavery. The finding of one or two objects of Russian origin with some of the mummies seems to indicate that the practice continued until a fairly recent date. A certain amount of cremation also appears to have been customary, and interesting and well-developed industries showing some degree of artistry were collected. The difficulties under which the expedition worked were very considerable, but nevertheless much valuable information has been added to our knowledge of these interesting peoples.

The practice of mummifying the dead, like that of trephination, is always intriguing. Why should these elaborate processes have been undertaken at all ? Connected as they often were with magic or religious. notions, their discovery sometimes throws a sidelight on the ideas of bygone peoples; whereas a study of the ordinary industries of such folk only determines their material culture--only tells us how they lived, not how they thought. Actually, mummifying has never been a common method of dealing with the dead either in modern or in ancient times. Egypt, of course, furnishes the classic example, but in the New World there were peoples both in South and North America who practised the rite. The orthodox diffusionist naturally claims that the custom in, say, Peru derived from Egypt; but frankly it is difficult to believe that the two or three prehistoric American peoples really had any connexion either with the Old World or with each other. It would seem far more likely to have been the result of a spontaneous development consequent upon a somewhat similar outlook on death.

\section{Floating Electric Power Plants}

Mr. A. C. Hardy, in an article entitled "The Electric Ship" in the Electrician of May 2, outlines. some recent trends and developments. A project for a $50,000 \mathrm{kw}$. self-contained, floating power plant. 